\title{
Tumors and Beyond: an Array of Abdominal Masses in Children
}

\author{
Surbhi Gupta ${ }^{1}$, Deepak Meena ${ }^{2 *}$, G L Meena ${ }^{1}$ \\ ${ }^{1}$ Department of Radio diagnosis, SP Medical College, Bikaner, Rajasthan. \\ ${ }^{2}$ Department of Dentistry, MG Medical College, Jaipur, Rajasthan.
}

Received: November 22, 2017, 2017; Accepted: December 29, 2017; Published: January 02, 2018

*Corresponding author: Deepak Meena, Department of Dentistry, MG Medical College, Jaipur, Rajasthan, India; E-mail: meenabkn@yahoo.co.in

\begin{abstract}
Aims and Objectives:

1. To provide insight into the different pediatric abdominal masses by Computed Tomography.

2. To characterize the various pediatric abdominal masses based on their imaging features.

Materials \& Methods: This observational study was conducted in Department of Radio-diagnosis at S.P. Medical College \& A.G. of Hospitals, Bikaner, Rajasthan. Data for the study was collected from patients of pediatric age group attending/ referred to the department of Radio-Diagnosis. An ultrasonographic examination was done in all cases using GE LOGIQ P5 USG machine. Doppler imaging was done in required cases. Non-contrast and contrast enhanced CT scan of the patients was carried out, using PHILIPS BRILLIANCE MDCT 64 SLICE CT SCAN. Scanning protocol was modified according to the age, weight of the child and the clinical situation. Imaging findings were correlated with the clinical course of disease and/or surgical/ cytological findings. The results were subjected to statistical analysis and expressed as percentages.
\end{abstract}

Conclusion: The recent developments have broadened the usefulness of Computed tomography in the evaluation of pediatric abdominal masses. The advantages of single breath hold acquisition in uncooperative children, improved vessel contrast enhancement, increased detection of lesions, and multiplanar and three dimensional reconstruction may make it one of the modalities of choice in diagnosis of abdominal masses in children.

Keywords: Abdomen; Computed Tomography; Wilms; Hepatoblastoma;

\section{Introduction}

Abdominal lumps in children include a variety of lesions of diverse origin. They may occur from the new born period through adolescence [1]. In most cases, there is absence of peculiar signs and symptoms that may aid in timely diagnosis. In many cases, the lesion is detected late after a long period of vague, nonspecific symptoms. The role of radiological imaging is to identify the precise location and extension of the pathologic process using the few essential imaging techniques.

Most abdominal masses in children are initially imaged by Plain X-ray. They provide information about the location of the mass and presence or absence of calcific component [1]. Their role ranges from a screening process, providing non-specific information in some cases, to providing specific information in some cases, to providing a specific diagnosis in others [2]. However, children are exposed to radiations and have limited role as only four basic densities (bone or mineral, soft tissue, fat, or air) are visualized [3].

Ultrasound is a powerful imaging modality for the pediatric patients since it does not have radiation hazard. It allows imaging in multiple planes, permits repetitive examinations and requires no physiologic function for anatomic visualization [2]. It can be used in directing a location for biopsies and drainage of fluid collections [4]. It aids in localizing the tumor, looking for associated lymphadenopathy and assessment of vascularity by Colour and Duplex Doppler. Thus, USG is diagnostic in some cases while limits the differential diagnoses in others and hence, is useful as a general screening procedure. However, USG is highly operator dependent and is adversely affected by bone or gas artefacts. In addition, ultrasonography provides less precise anatomic details $[4,5,6]$.

In recent times, computed tomography has found increasing application in the evaluation of pediatric abdominal masses [2]. The anatomic detail provided by CT is superior to any other imaging modality currently available. It obtains an entire anatomic section of tissue, which aids in determining the precise extent of disease. It is not operator dependent and permits the accurate measurement of tissue attenuation coefficient. Enhancement with contrast medium facilitates measurement of blood flow to an organ or pathologic abnormality $[7,8]$. However, the paucity of tilt in children makes delineation of anatomic margins in the retroperitoneum difficult [9]. In addition, conventional CT requires sedation in infants and small children, intravenous and enteric contrast medium, immobilization and alteration of environment, and is time consuming $[10,11]$.

Thus, Multislice helical technology has expanded the usefulness of CT in evaluation of pediatric abdominal masses [12]. The advantages of single breath-hold acquisition in cooperative children, improved vascular contrast enhancement, increased detection of parenchymal lesions and multiplaner and three- 
dimensional reconstructions may make it one of the modalities of choice in evaluation of pediatric abdominal masses $[13,14,15]$.

\section{Material \& Methods}

This observational study was conducted in Department of Radio-diagnosis at S.P. Medical College \& A.G. of Hospitals, Bikaner, Rajasthan.

\section{Source of Data}

Data for the study was collected from patients of pediatric age group attending/ referred to the department of Radio-Diagnosis.

\section{Inclusion Criteria}

All patients 0 to 14 yrs who have clinical suspicion as well as ultrasonographic evidence of mass in abdomen.

\section{Exclusion Criteria}

- Patients above the age of 14 yrs.

- Patients with bleeding diatheses.

- Patients with previous history of contrast sensitivity.

\section{Methods}

A detailed clinical history was recorded followed by relevant clinical examination. An ultrasonographic examination was done in all cases using GE LOGIQ P5 USG machine. Doppler imaging was done in required cases. Non-contrast and contrast enhanced CT scan of the patients was carried out, using PHILIPS BRILLIANCE MDCT 64 SLICE CT SCAN. Scanning protocol was modified according to the age, weight of the child and the clinical situation. Imaging findings were correlated with the clinical course of disease and/or surgical/cytological findings. The results were subjected to statistical analysis and expressed as percentages.

\section{Results}

The majority of neonatal masses are retroperitoneal in location (52\%) out of which 54\% are of renal origin [6].Paediatric abdominal masses occurring after the neonatal period are still predominantly retroperitoneal; however, there is a significant increase in malignant tumours and some differences in the incidence of specific masses[2]. We studied 50 cases of paediatric abdominal masses in various age groups. Quite a large spectrum of lesions was found.

\begin{tabular}{|c|c|c|}
\hline Table 1: Age Distribution & & \\
\hline Age Group & No. of Cases & Percentage \\
\hline$\leq 1$ year & 8 & 16 \\
\hline $1-5$ years & 21 & 42 \\
\hline$>5$ years & 21 & 42 \\
\hline Total & 50 & 100 \\
\hline Maximum: More than 1 yr & & \\
\hline
\end{tabular}

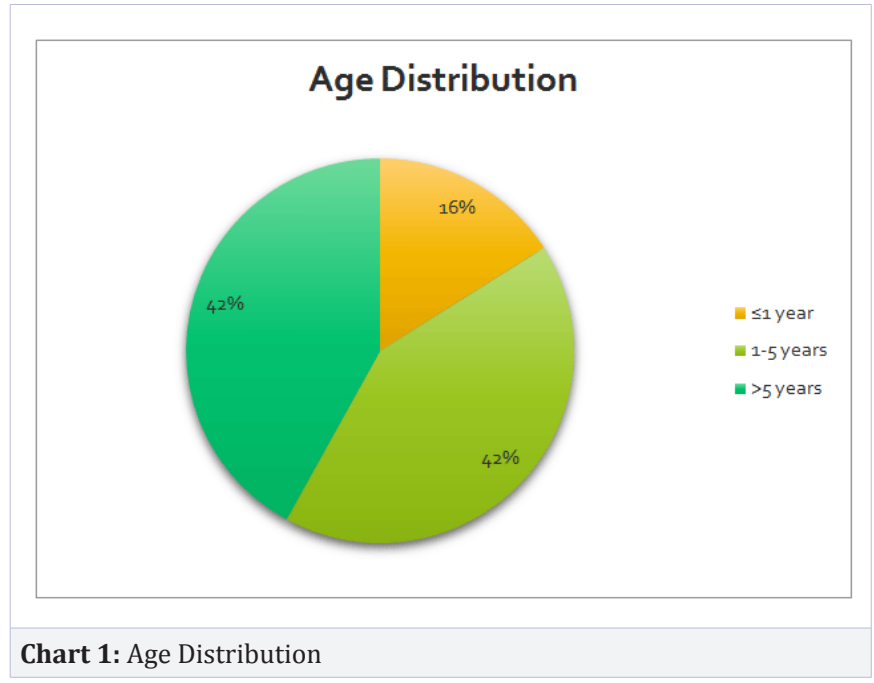

Biona et. al, in 1983 and Rastogi et. al in 1988 reviewed the pattern of paediatric abdominal masses $[16,17]$. The age wise incidence in our series in 3 defined groups was $16 \%(8 / 50)$ in $0-1$ years, $44 \%(22 / 50)$ in $1-5 y e a r s$ and $40 \%(20 / 50)$ in > 5years (Table1, Chart 1). In our study, the male: female ratio was 29:21 i.e. 1.4:1 (Table2, Chart 2).

\begin{tabular}{|c|c|c|}
\hline Table 2: Sex distribution & \multicolumn{2}{|c|}{} \\
\hline Category & $\begin{array}{l}\text { Number of } \\
\text { Cases }\end{array}$ & Percentage (\%) \\
\hline Male & 29 & 58 \\
\hline Female & 21 & 42 \\
\hline Total & 50 & 100 \\
\hline Maximum: Males 58\% & & \\
\hline
\end{tabular}

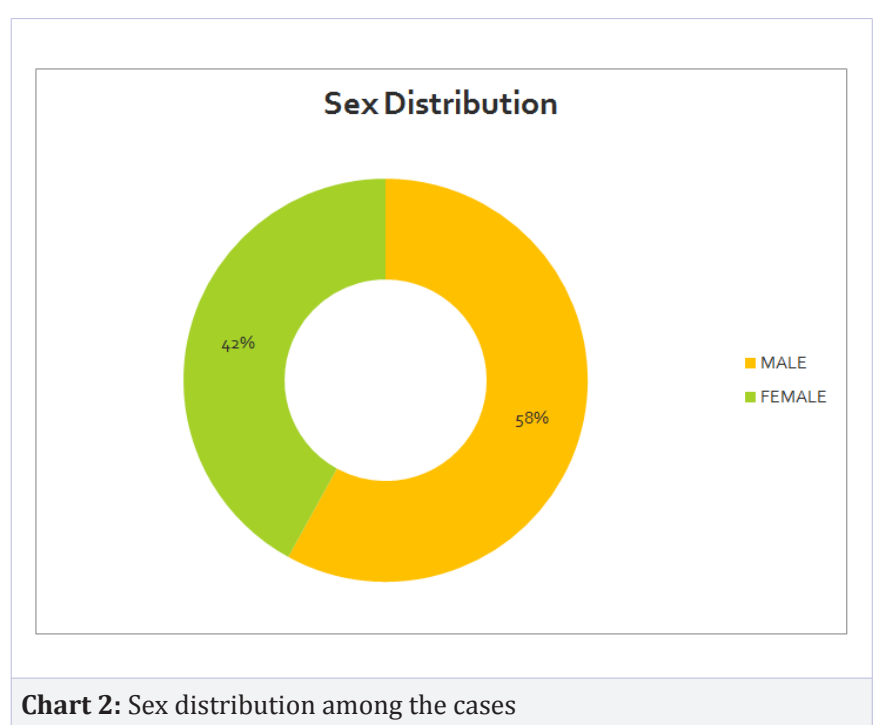


Majority of the patient presented with progressively increasing abdominal lump (Table 3, Chart 3) and USG was the initial investigation requested (Table 4, Chart 4). In our study, out of 50 cases $22(44 \%)$ were malignant and 28 (56\%) were benign. This is in accordance with incidence reported by Rastogi et al where 58\% passes were benign (Table 5, Chart 5). However, in Biona series, excluding hydronephrosis 18 of the 26 cases (70\%) were malignant $[16,17]$

Table 3: Various clinical signs/symptoms of presentation

\begin{tabular}{|c|c|c|}
\hline $\begin{array}{c}\text { Presenting } \\
\text { symptoms/signs }\end{array}$ & No. of cases & Percentage \\
\hline $\begin{array}{c}\text { Lump in } \\
\text { abdomen/back }\end{array}$ & 23 & 44 \\
\hline Pain in abdomen & 19 & 37 \\
\hline $\begin{array}{c}\text { Abdominal } \\
\text { distension }\end{array}$ & 15 & 32 \\
\hline Vomiting & 4 & 9 \\
\hline Fever & 8 & 11 \\
\hline Hematuria & 2 & 4 \\
\hline Icterus & 2 & \\
\hline Maximum: Lump in abdomen-44\% & \\
\hline
\end{tabular}

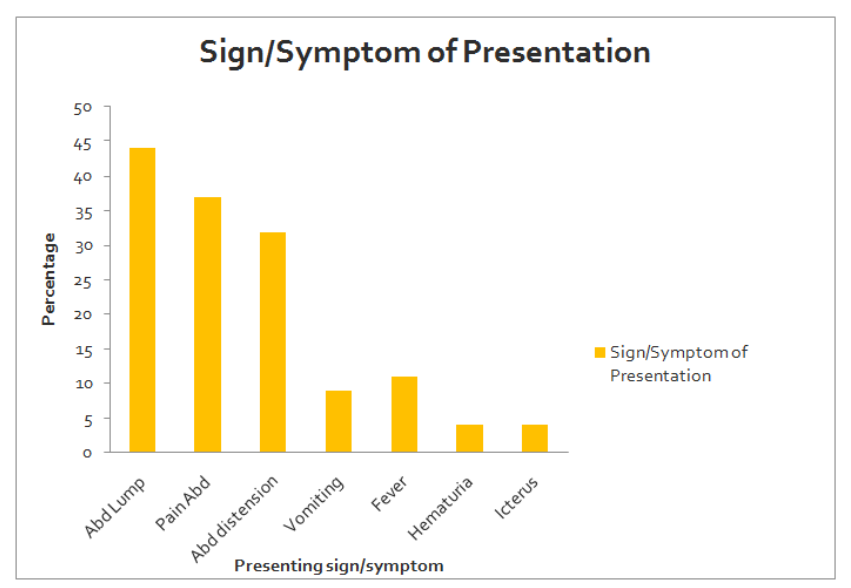

Chart 3: Presenting signs and symptoms

Table 4: Initial investigation for which patient was referred

\begin{tabular}{|c|c|c|}
\hline Investigation & No. of cases & Percentage \\
\hline Plain radiograph & 2 & $4 \%$ \\
\hline Contrast study & 0 & $0 \%$ \\
\hline USG & 44 & $88 \%$ \\
\hline CT & 4 & $8 \%$ \\
\hline Maximum: USG- 88\% & & \\
\hline
\end{tabular}

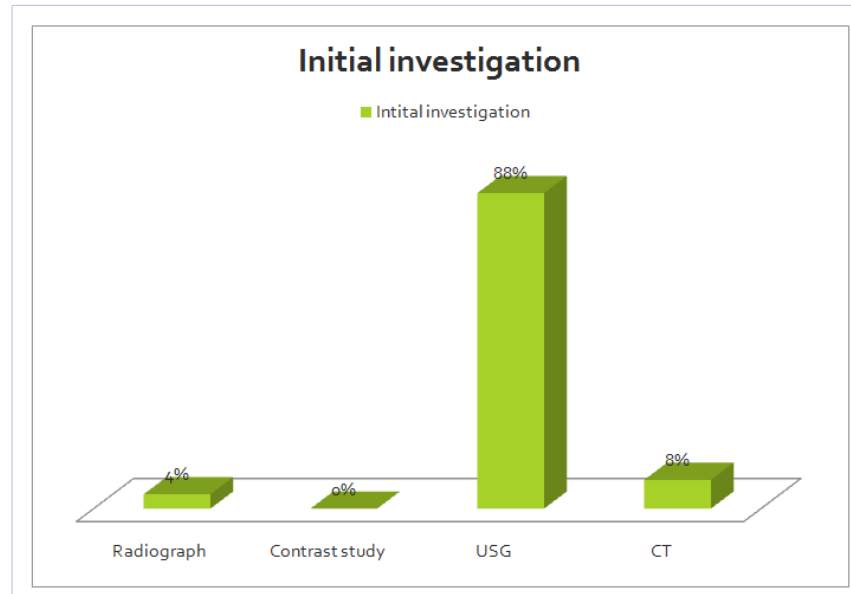

Chart 4: Initial investigation requested

Table 5: Distribution of masses according to nature

\begin{tabular}{|c|c|c|}
\hline Nature of Mass & No. of cases & Percentage \\
\hline Malignant & 22 & $44 \%$ \\
\hline Benign & 28 & $56 \%$ \\
\hline Congenital & 3 & $6 \%$ \\
\hline $\begin{array}{c}\text { Infective/ } \\
\text { Inflammatory }\end{array}$ & 13 & $26 \%$ \\
\hline Neoplastic & 4 & $8 \%$ \\
\hline Miscellaneous & 7 & $14 \%$ \\
\hline
\end{tabular}

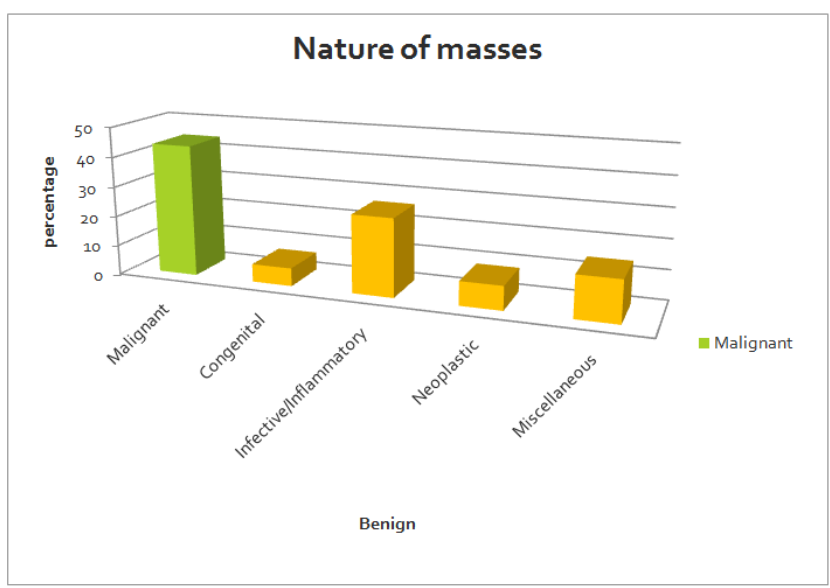

Chart 5: Distribution of masses according to nature

In our study, $52 \%(26 / 50)$ of the masses were retroperitoneal out of which 14 (54\% of retroperitoneal and 28\% of total) were renal (Table 6, Chart 6), an incidence quite similar to that reported by Biona et al (58\% retroperitoneal and 31\% renal) and Rastogi et al (53\% retroperitoneal and 32\% renal). Egeibor and Jabral also state that the majority of the abdominal masses occurring in childhood are retroperitoneal in location, and greater than $50 \%$ of these masses arise from the kidney $[16,17,18]$. 


\begin{tabular}{|c|c|c|c|c|c|}
\hline Location & $\leq 1$ year & 1-5years & $>$ 5years & Total & Percentage \\
\hline Renal & 3 & 7 & 4 & 14 & $28 \%$ \\
\hline Non-renal retroperitoneal & 0 & 7 & 1 & 8 & $16 \%$ \\
\hline Genital & 0 & 2 & 4 & 6 & $12 \%$ \\
\hline Gastro-intestinal/Mesentric & 0 & 0 & 6 & 6 & $12 \%$ \\
\hline Hepatobiliary & 1 & 3 & 4 & 8 & $16 \%$ \\
\hline Others & 4 & 2 & 2 & 8 & $16 \%$ \\
\hline Total & 7 & 19 & 17 & 50 & $100 \%$ \\
\hline
\end{tabular}

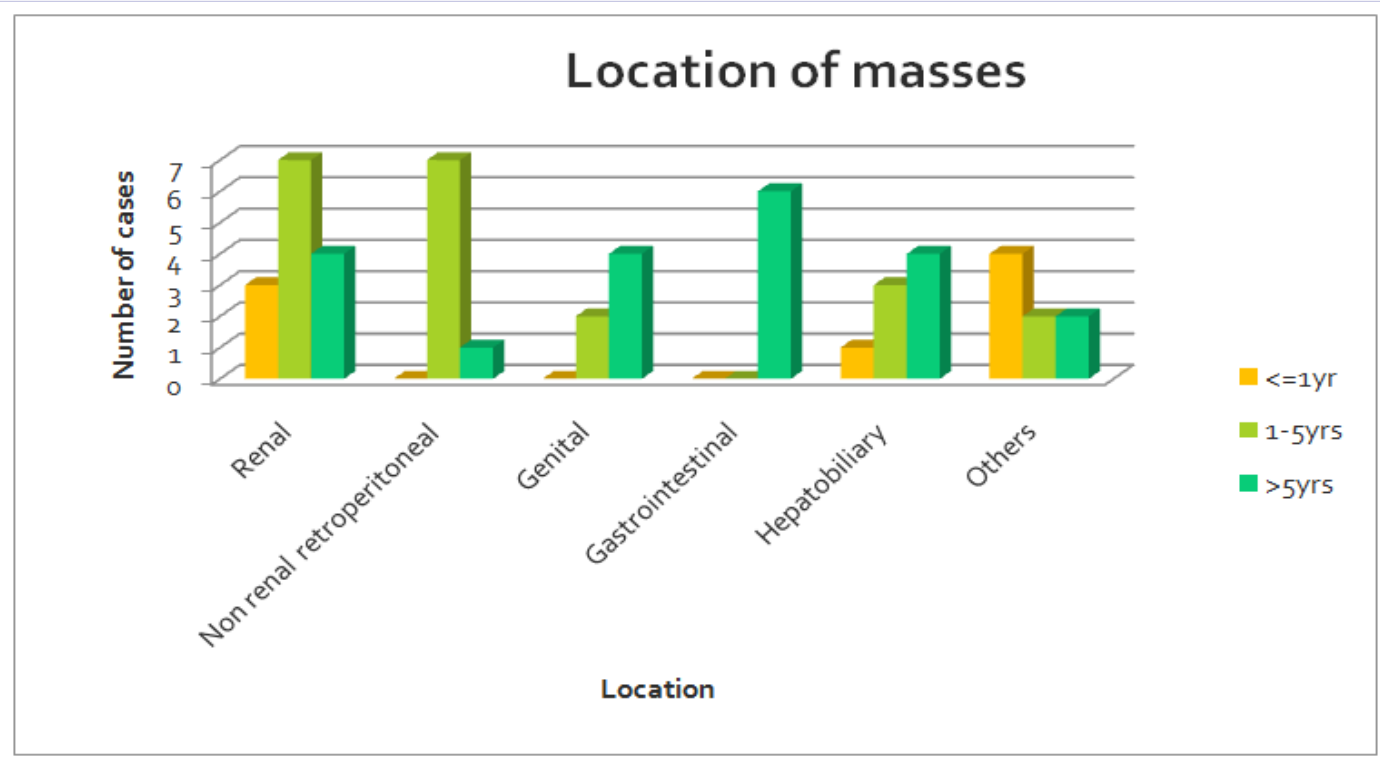

Chart 6: Showing location of masses in various age groups

Out of the 14 renal masses, 8 were neoplastic (57\%). Out of these $5(62.5 \%)$ had Wilms' tumor (Figure 1), 1 had rhabdoid tumor of kidney and 1 had renal cell carcinoma (Table 7). In cases reported by Rastogi et al, $63 \%$ of renal lesions were neoplastic and all had Wilms' tumor while in Biona series, all the renal masses (exclusive of hydronephrosis) had Wilms' tumor[16,17,19]. (Figure 2)

Non-renal retroperitoneal masses constituted 24\% (12/50) of the cases (Table 6, Chart 6). This is similar to the incidence reported by Griscom (29\%), Rastogi et al (20\%) and Biona et al (30\%). Out of these, 6 cases were of neuroblastoma (50\%) (Figure 3 ). In series by Griscom3, neuroblastoma constituted 60\% of non-renal retroperitoneal cases while in series by Rastogi et al and Biona et al, $39 \%$ and $11.8 \%$ were neuroblastomas $[3,16,17]$.

Next category of masses included those of gastro intestinal /mesenteric origin (Table 7). These constituted 12\% (6/50) of total cases as compared to $32 \%$ in Rastogi series. However, in cases illustrated by Griscom, 16\% cases were of gastrointestinal/ mesenteric origin while Biona series had only 2 such cases
$[6,16,17]$. Out of the cases in our study, all 6 children were $>5$ years of age. The diagnosis included mesenteric lymphangioma, chronic midgut volvulus, omphalomeseneric cyst (Figure 4).

Hepatobiliary masses contributed $8(16 \%)$ cases. Out of these, 2 cases were of hepatoblastoma (Figure 5), one of Hepatocellular carcinoma, and one of choledochal cyst (Figure 6). Cases of liver abscess and hydatid cyst were also observed (Figure 7).

Cases involving genital system were also found 6/50 (12\%). Of these 1 was malignant (dysgerminoma) while others were benign and included teratoma, ovarian cysts and ovarian tortion (Figure 8).

USG and CT were done in every patient. While USG was found quite useful in majority of the cases, its accuracy was found to be consistently less as compared to CT in all aspects. While the accuracy of USG in predicting nature of the mass, its localisation, extent and exact diagnosis was $81 \%, 64.5 \%, 59 \%$ and $54.5 \%$ respectively, the accuracy of CT for same was found to be $100 \%$, $97 \%, 100 \%$ and $81 \%$ respectively (Table8, Chart 7). 

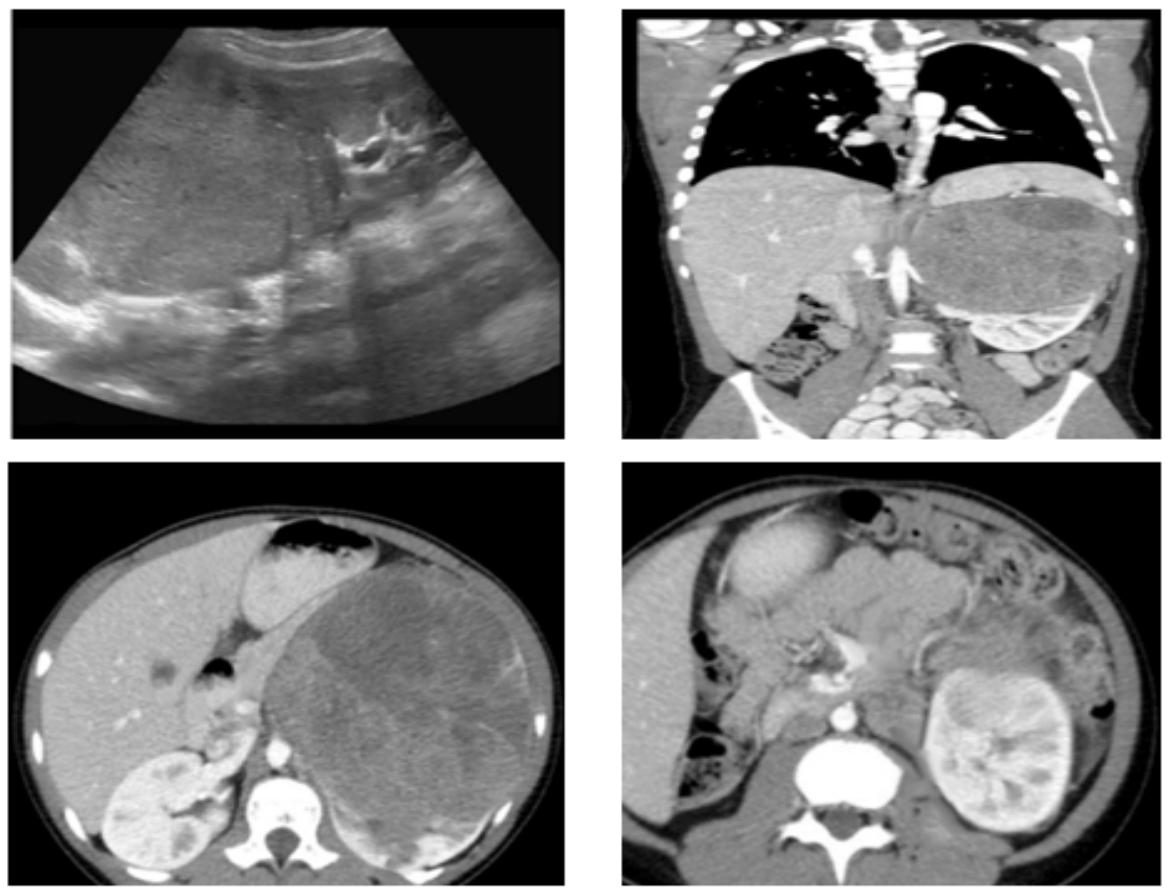

Figure 1 (Wilm's Tumor): Clockwise: On sagittal US image of the left kidney, a large mass can be demonstrated as a

hypoechoic mass in the upper pole of the kidney. Reformatted coronal and axial contrast-enhanced CT images demonstrate a larger mass with well-defined contours in the upper pole of the left kidney. There is a nodular heterogeneous lymph node in para-aortic region.

Table 7: Percentage of masses according to diagnosis

\begin{tabular}{|c|c|c|c|c|c|}
\hline Diagnosis & $\leq 1$ year & 1-5 yrs & $>5$ years & Total & Percentage \\
\hline Wilm's tumor & 0 & 3 & 2 & 5 & $10 \%$ \\
\hline Neuroblastoma & 0 & 6 & 0 & 6 & $12 \%$ \\
\hline Mesentric cyst/lymphangioma & 0 & 0 & 2 & 2 & $4 \%$ \\
\hline Perinephric/renal abscess & 1 & 0 & 1 & 2 & $4 \%$ \\
\hline Abdominal wall abscess & 1 & 0 & 0 & 1 & $2 \%$ \\
\hline Rhabdoid tumor of kidney & 0 & 1 & 0 & 1 & $2 \%$ \\
\hline Renal cell carcinoma & 0 & 0 & 1 & 1 & $2 \%$ \\
\hline Hepatoblastoma & 0 & 2 & 0 & 2 & $4 \%$ \\
\hline Hepatocellular carcinoma & 0 & 0 & 1 & 1 & $2 \%$ \\
\hline Liver abscess & 1 & 0 & 2 & 3 & $6 \%$ \\
\hline Retroperitoneal yolk sac tumor & 0 & 1 & 0 & 1 & $2 \%$ \\
\hline Hydatid cyst & 0 & 1 & 1 & 2 & $4 \%$ \\
\hline $\begin{array}{l}\text { Hydroureteronephrosis/ } \\
\text { Hydronephrosis }\end{array}$ & 1 & 1 & 0 & 2 & $4 \%$ \\
\hline Psoas abscess & 0 & 1 & 0 & 1 & $2 \%$ \\
\hline Iliocaecal TB & 0 & 0 & 1 & 1 & $2 \%$ \\
\hline Lymphoma & 0 & 1 & 1 & 2 & $4 \%$ \\
\hline Midgut volvulus & 0 & 0 & 1 & 1 & $2 \%$ \\
\hline Multicystic dysplastic kidney & 1 & 0 & 0 & 1 & $2 \%$ \\
\hline Embryonal rhabdomyosarcoma & 0 & 1 & 1 & 2 & $4 \%$ \\
\hline Cystic nephroma of kidney & 0 & 1 & 0 & 1 & $2 \%$ \\
\hline
\end{tabular}

Citation: Surbhi Gupta, Deepak Meena, et al. (2017) Tumors and Beyond: an Array of Abdominal Masses in Children. Int J pediatr 


\begin{tabular}{|c|l|l|l|l|l|}
\hline Sacro-coccygeal teratoma & 1 & 0 & 0 & 1 & $2 \%$ \\
\hline Pelvic teratoma & 0 & 1 & 1 & 2 & $4 \%$ \\
\hline Choledochal cyst & 0 & 0 & 1 & 2 & 2 \\
\hline Ovarian cyst & 0 & 0 & 1 & 1 & $2 \%$ \\
\hline Ovarian torsion & 0 & 0 & 0 & 1 & $2 \%$ \\
\hline Heterotaxy syndrome & 1 & 0 & 1 & 1 & $2 \%$ \\
\hline Appendicular abscess & 0 & 0 & 1 & 1 & $2 \%$ \\
\hline Malignant Dysgerminoma & 0 & 0 & 0 & 1 & $2 \%$ \\
\hline Pseudopancreatic cyst & 0 & 0 & & 50 \\
\hline Hemorrhagic adrenal cyst & 1 & & & $100 \%$ \\
\hline Total & & & & $2 \%$ \\
\hline
\end{tabular}

Maximum: Neuroblastoma-12\%
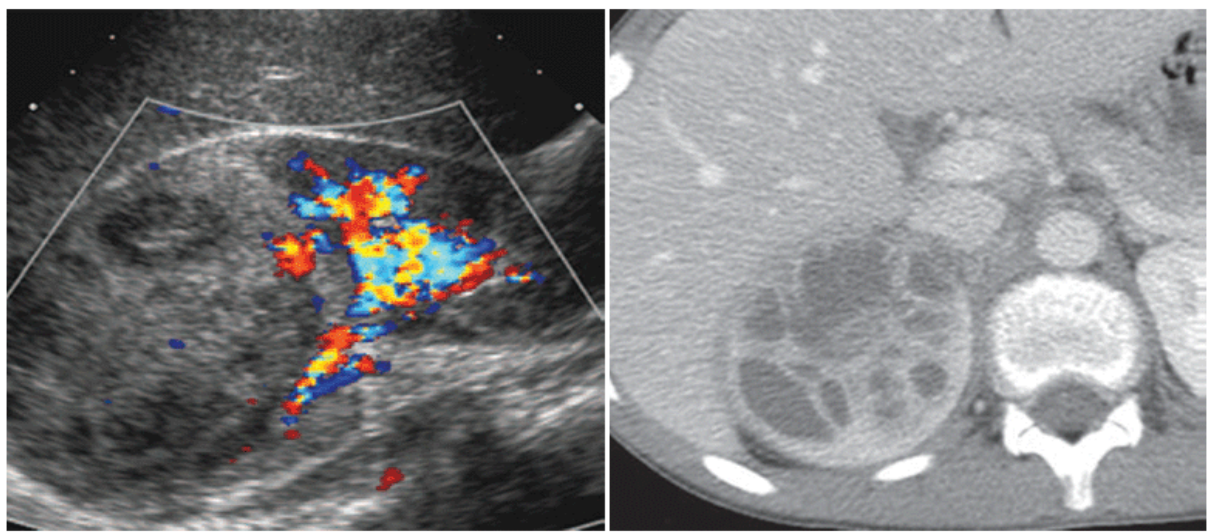

Figure 2 (Renal abscess): Right: Transverse ultrasound image of right kidney shows avascular heterogeneous area in upper and mid zones. Left: Contrast-enhanced axial CT image shows heterogeneous lesion with multiple internal septations of varying thickness in right kidney.

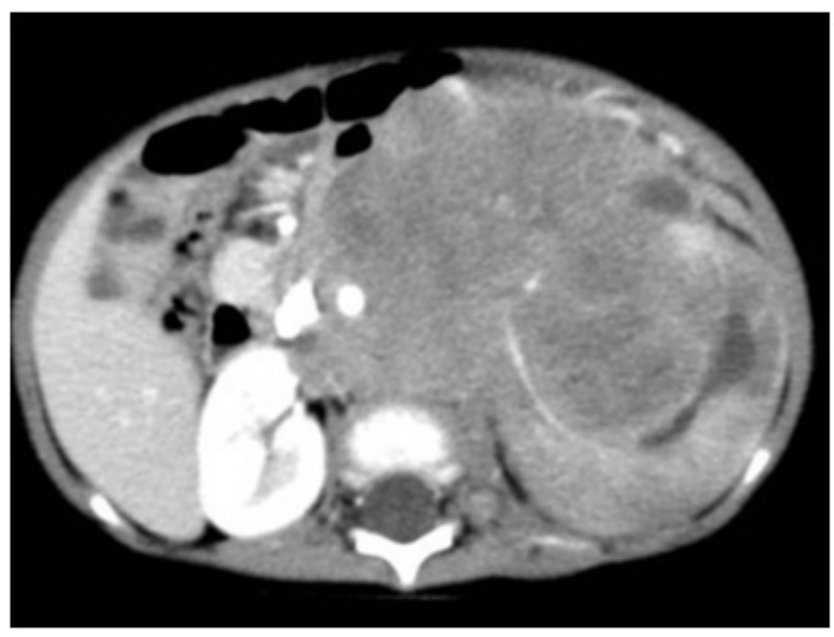

Figure 3 (Neuroblastoma): Neuroblastoma; Axial CT scans shows a large soft tissue mass, with areas of necrosis, crossing the midline and encasing and anteriorly displacing the aorta and inferior vena cava

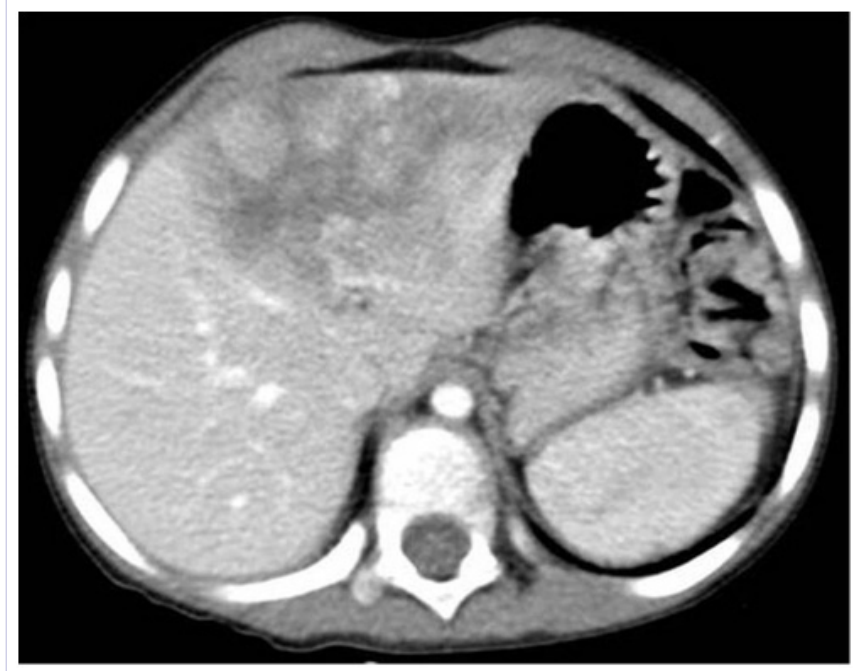

Figure 5 (Hepatoblastoma): Axial Contrast enhanced CT shows heterogeneously enhancing mass lesion in the left lobe of liver. 

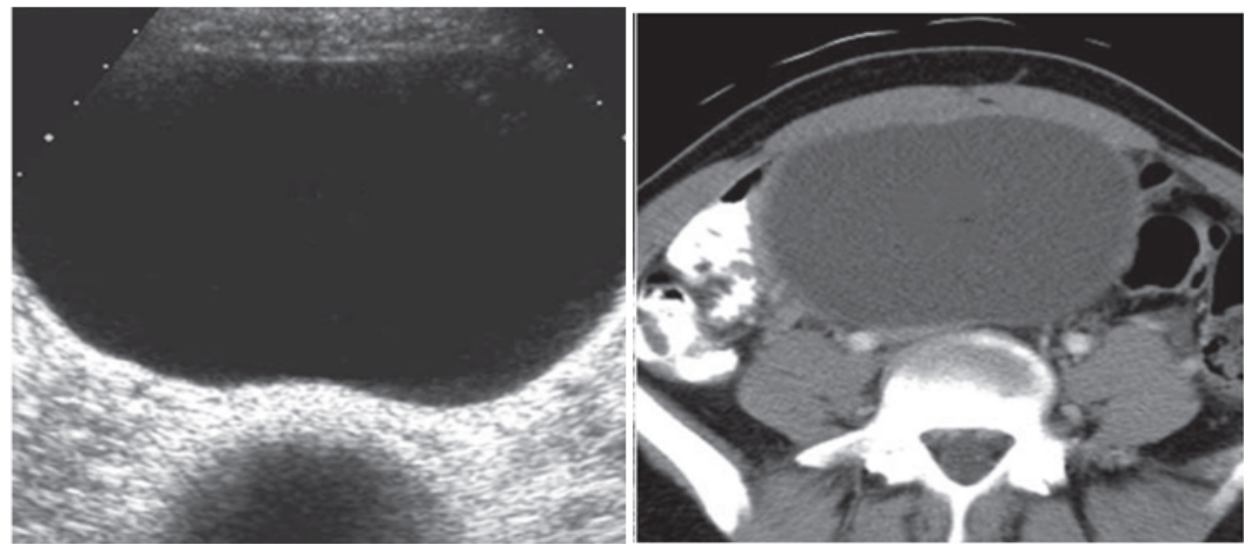

Figure 4 (Mesenteric cyst): Transverse ultrasound image of mid abdomen shows large anechoic cystic mass with imperceptible wall.Contrast-enhanced axial CT image shows well-circumscribed cystic mass without enhancement inmidabdomen.

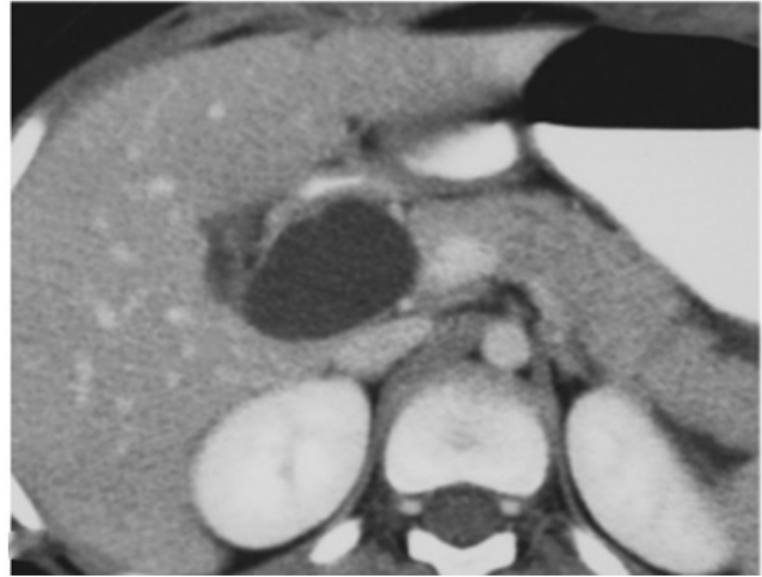

Figure 6 (Choledochal cyst): CT scan of a child shows a well-defined cyst in the porta hepatis associated with dilated central hepatic ducts.

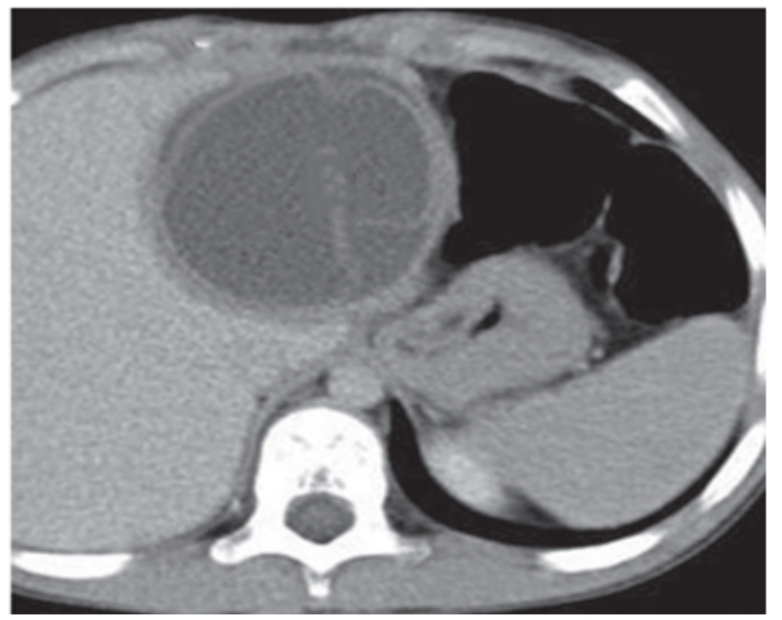

Figure 7 (Hydatid cyst of liver): Contrast-enhanced axial CT image shows well-defined cystic mass with several internalendocyst membranes.

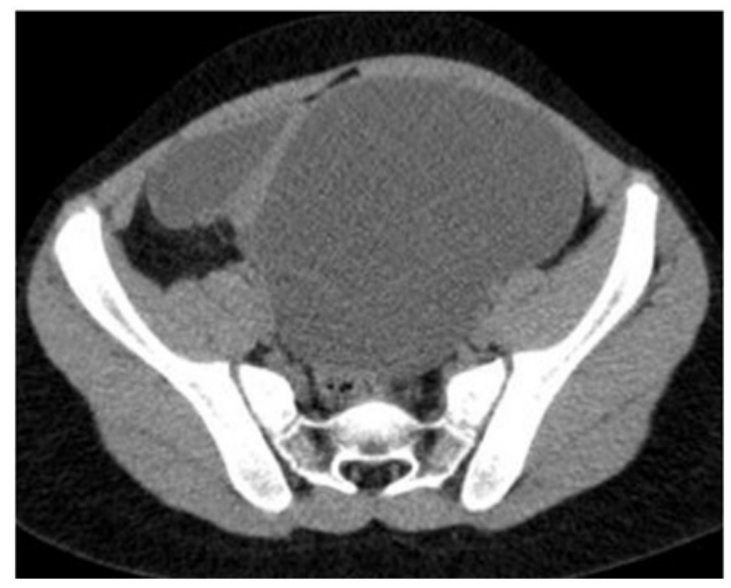

Figure 8 (Ovarian Cyst): Axial CT shows a large ovarian cyst displacing and compressing the urinary bladder is typically hypodense, sharply demarcated with a smooth thin wall.

Table 8: Accuracy of CT and USG vis-à-vis surgical/cytological findings

\begin{tabular}{|c|c|c|}
\hline & USG & CT \\
\hline Nature of Mass & $81 \%$ & $100 \%$ \\
\hline Localization & $64.5 \%$ & $97 \%$ \\
\hline Extent & $59 \%$ & $100 \%$ \\
\hline Diagnosis & $54.5 \%$ & $86 \%$ \\
\hline
\end{tabular}

\section{Conclusion}

An abdominal mass in an infant presents a challenging diagnostic problem. Preoperative study of abdominal masses is a problem of primary importance in paediatric age group [20].

In last many years, Computed Tomography has been established as the imaging modality of choice for evaluation of paediatric abdominal masses [21]. Recently the introduction of multisclice multidetector helical CT has resulted in improved spacial and temporal resolution with reduction in scan acquisition and display time from minutes to seconds, while at the same time allowing acquisition of volume data [22,23]. 


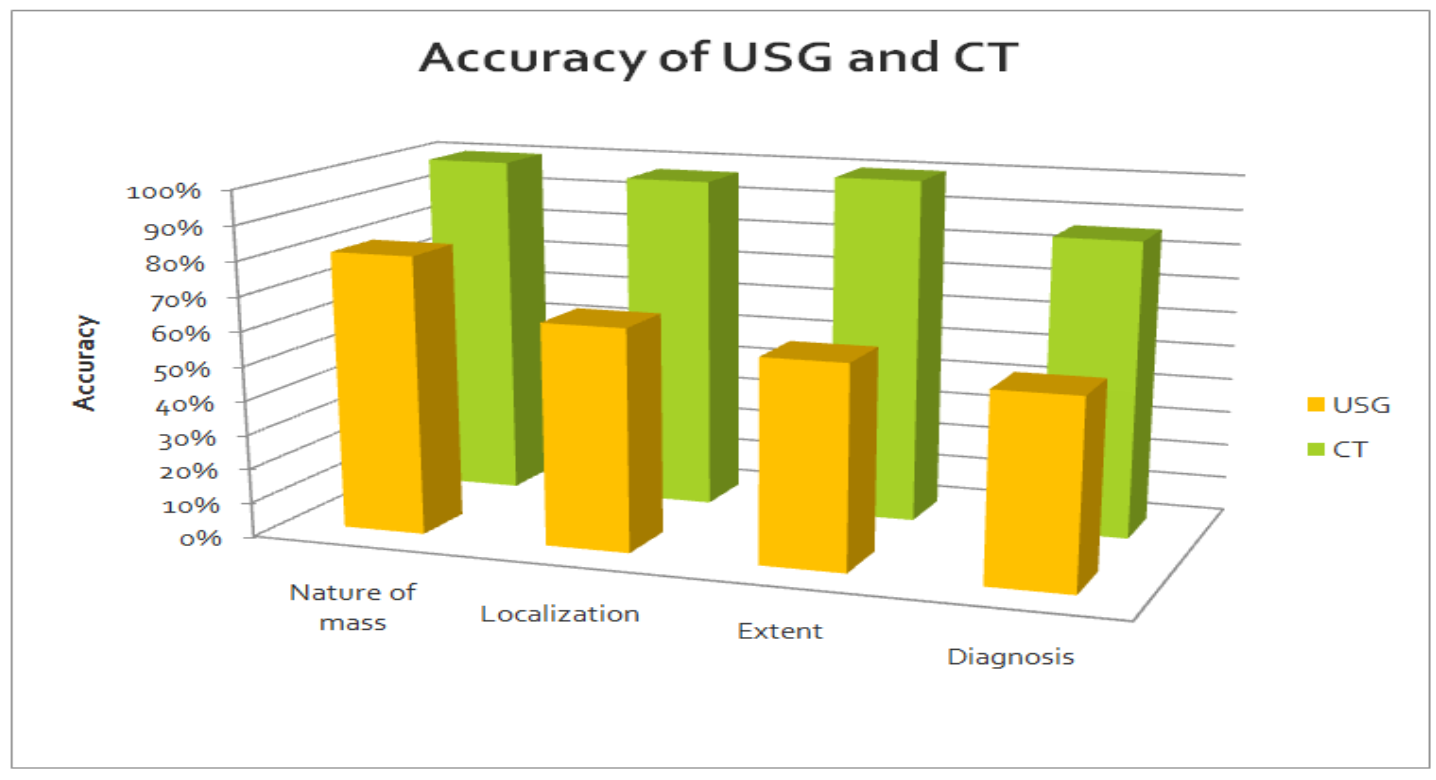

Chart 7: Accuracy of CT and USG vis-à-vis surgical/cytological findings

While CT was found to be $100 \%$ accurate in determining the exact location as well as extent of the mass lesions, the accuracy for diagnosis was found to be $81 \%$ reflecting the inherent limitation of the imaging modality in terms of non specific findings in certain lesions. An important aspect was optimal vascular enhancement and excellent multiplanar reconstructions with CT that enabled an appropriate evaluation of the extent of the lesion as well as relation of the mass to various vessels at the same time also conclusively telling about vascular invasion, an important finding in context of various malignancies and their staging [24,25]. In context of children, the motion artifacts encountered in our study were very infrequent and in no case were they of such significance as to impede the diagnostic value of the examination.

Thus we would conclude that the recent advances have expanded the usefulness of CT in the evaluation of paediatric abdominal masses $[26,27]$. The advantage of single breath hold acquisition in cooperative children, improved vascular contrast enhancement, increased detection of parenchymal lesions, and multiplanar and three dimensional reconstruction may make it one of the modalities of choice in evaluation of paediatric abdominal masses.

\section{References}

1. Merten DF, Stuart GH. Radiological staging of thoracoabdominal tumors in childhood. Radiologic clinics of North America. 1994;32(1):133-149.

2. Goldberg BB, Pollack HM,Capitanio MA, KirkpatrickJA.Ultrasonography: an aid in the diagnosis of masses in paediatric patients. Paediatrics. 1975;56(3):421-428.

3. Griscom NT. The roentgenology of neonatal abdominal masses. AJR. 1965;93:447-463.

4. Yamaguchi M, Takeuchi S, Akiyama H, Sawaguchi S. Ultrasonic evaluation of abdominal masses in the paediatric patient. Tohoku J Exp Med. 1980;130(1):25-39.
5. Scott DJ, Wallace WH, Hendry GM. With advances in radiological imaging can the radiologist reliably diagnose Wilm's tumor? Clin. Radiol. 1999;54(5):321-327.

6. Ohtsuka Y, Takahashi H, Ohnuma N, Tanabe M, Yoshida H, Iwai J. Detection of tumor thrombus in children using colour Doppler ultrasonography. J. Paed. Surgery. 1997;32(10):1507-1510.

7. Riccabona M, Uggowitzer KE, Lindbichler F, Ebner F, Fotter R. Echoenhanced color Doppler ultrasonography in children and adolescents. J Ultrasound Med. 2000;19(11):789-796.

8. Bates SM, Keller MS, Ramos IM, Carter D, Taylor KJ. Hepatoblastoma: Detection of tumor vascularity with duplex Doppler US. Radiology. 1990;176(2):505-507.

9. Plumley DA, Grosfeld JL, Kopecky KK, Buckwalter KA, Vaughan WG: The role of spiral CT with 3D reconstruction in pediatric solid tumors. J Pediatr Surg. 1995;30(2):317-321.

10.Miele V, Galluzo M, Bellusi A, Valenti M. Spiral CT in the study of renal neoplasms in children. Radiol Med (Torino). 1998;95(5):486-492.

11.Frush DP, Siegel MJ, Bisset GS. 3rd: Challenges of pediatric spiral CT. Radiographics. 1997;17(4):939-959.

12.Gualdi GF, Ferriano MG, Casciani E, Pollettini E. Volumetric Spiral CT in the diagnosis, staging and programmed therapy of kidney tumors: Comparison with conventional CT. Clin Ter. 1998;149(5):335-341.

13.Gilbert R, Garra B, Gibbons MD. Renal Duplex Doppler Ultrasound: An adjunct in the evaluation of hydronephrosis in the child. J Urol. 1993;150(4):1192-1194.

14.Lim GY, Jang HS, Lee EJ, Lim YS, Jung SE, Lee JM, et al. Utility of the resistance index ratio in differentiating obstructive from nonobstructive hydronephrosis in children. J Clin Ultraound. 1999;27(4):187-193.

15.Report of the international Reflux Study Committee. Medical versus Surgical treatment of primary vesicoureteral reflux: a prospective international reflux study in children. J Urol. 1981; 125(3): 277-283.

16.Biona K, Bazaz R, BhargavaS. Roentgen evaluation of abdominal masses in children. IJRI 1983;37(4):337-342. 
17.Rastogi V, Singhal PK, Aseri A, Taneja SB. Ind J Ped. 1988;55:295-300.

18.Egeibor 00 and Jebral AA. Pediatric renal masses: CT findings. Applied Radiology, 1999;28(2):20-26.

19.Berrocal T, Gaya F, Arjonilla A, Lonergan GJ. Vesicoureteral Reflux: Diagnosis and grading with Echo-enhanced cystosonography versus voiding cystourethrography. Radiology. 2001;221(2):359-365.

20.Agarwal R. Sonographic assessment of fetal abdominal cystic lesions. A pictorial essay. Ind. Journal Radiol Img. 1999;9(4):169-182.

21.Ganeshan S, Indrajit IK. Images: Prune Belly Syndrome: Antenatal Ultrasound. Ind Journal Radiol Img. 2001;11(1):25-28.

22.Lee EY. CT imaging of mass-like renal lesions in children. Pediatr Radiol. 2007;37(9):896-890.
23.Toma Paolo, Claudio Granata, Andrea Rossi, Alberto Garaventa. Multimodality Imaging of hodgkindisease and non-hodgkinlymphomas in children. Radiographics. 2007;27(5):1335-1354.

24.d'Almeida M, Jose J, Oneto J, Restrepo R. Bowel wall thickening in children: CT findings. Radiographics. 2008;28(3):727-746.

25.Ranganath SH, Lee EY, Eisenberg RL. Focal cystic abdominal masses in pediatric patients. Am J Roentgenol. 2012;199(1):1-16.

26.Pickhard TP, Sanjeev B. Primary Neoplasms of Peritoneal and Subperitoneal Origin: CT findings. Radiographics. 2005;25:983-995.

27.Blevrakis E, Tavladaki T, Spanaki A, Vasilaki E, Ilia S, Geromarkaki E, et al. 680 Intra-Abdominal Tumors in Children Archives of Disease in Childhood. 2012;97(2):A196-A197. 